\title{
Developing a New Technical Strategy for Rail Infrastructure in Low-Income Countries in Sub-Saharan Africa and South Asia
}

\author{
Marcelo Blumenfeld * (1), Wendy Wemakor, Labib Azzouz and Clive Roberts $(\mathbb{D}$ \\ Birmingham Centre for Railway Research and Education, University of Birmingham, Birmingham B15 2TT, UK \\ * Correspondence: m.blumenfeld@bham.ac.uk
}

Received: 5 July 2019; Accepted: 6 August 2019; Published: 9 August 2019

check for updates

\begin{abstract}
Low-income countries (LICs) in Sub-Saharan Africa and South Asia are investing in new railway lines to replace deteriorated infrastructure from the 19th and 20th century. These actions, despite financial and economic constraints, have been justified in common visions of continent-wide efficient networks to cope with the demands of growing populations. However, most of the recent rail infrastructure projects are driven by international suppliers' preferences and financing rather than creating railways that match the requirements of interoperable regional networks. This paper therefore explores the current status of rail infrastructure in these LICs and the operational performance achieved to understand specific capability gaps in each regional network. Drawing from the experience of European countries in transforming regional future visions into applied research, a technical strategy for rail infrastructure in LICs is proposed. The strategy captures the key capabilities to be addressed in order to achieve future performance goals, while emphasizing the need for emerging technologies to be used in fit-for-purpose solutions. It is envisioned that the strategy will provide the basis for the development of continental technical strategy programs with specific technology roadmaps towards a common goal.
\end{abstract}

Keywords: capability plan; low-income countries; railways; railway technical strategy; South Asia; Sub-Saharan Africa; sustainability

\section{Introduction}

While road transport has been the dominant mode for the movement of people and goods since the mid-1900s, railways are now staging a global comeback, illustrated by growth in the total length of rail tracks and overall rail traffic units per year (passenger-km and tonne-km) [1]. Among the various reasons for their renaissance are the concerns over the significant social, economic, and environmental externalities created by the transport sector. Global greenhouse gas emissions from the transport sector have more than doubled since 1971, and over three quarters of this increase has come from road vehicles [2]. Rail transport is potentially more environmentally friendly than its road counterpart in terms of energy consumption and emissions per traffic unit. Railways are costly to build and maintain but can produce significantly lower external costs than other modes of transport, particularly when carrying freight.

Either powered by diesel or electricity, the railways can reduce external costs of transport by at least $47.5 \%$ per passenger-km, and $75.4 \%$ per tonne- $\mathrm{km}$ when compared to road modes (see Figure 1) [3]. The biggest savings are found in environmental impacts, such as air pollution and climate change. Rail freight produces between $75 \%$ and $85 \%$ less greenhouse gas emissions per transport unit when compared to articulated trucks, monetizing its benefit at around 0.1-0.4 cents per net tonne-km [4]. 


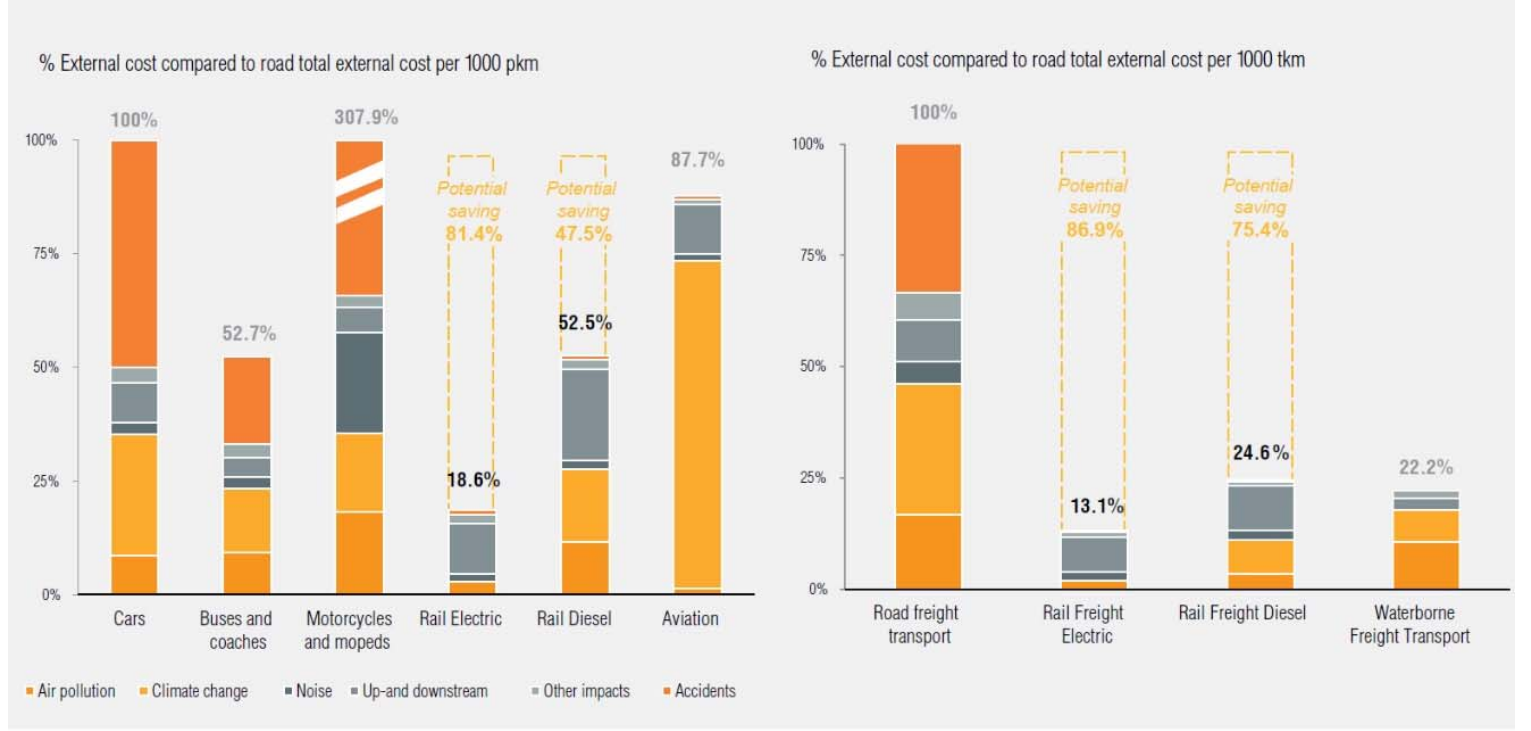

Figure 1. External costs of railways compared to other modes of transport [4].

The compound annual growth of rail freight transport has been positive around the world in the last three decades [4]. For passenger services, the compound annual growth rate (CAGR) has varied across different continents, as shown in Figure 2. However, the inferior performance of most low-income countries in both passenger and freight transport is evident. As a whole, with few exceptions, low-income countries have experienced low growth in freight transport and a drop in the passenger railway market. The graph for the South Asia region does not illustrate the situation in its low-income countries because the growth in traffic units has happened mostly in India (which is not considered a low-income country by the World Bank).

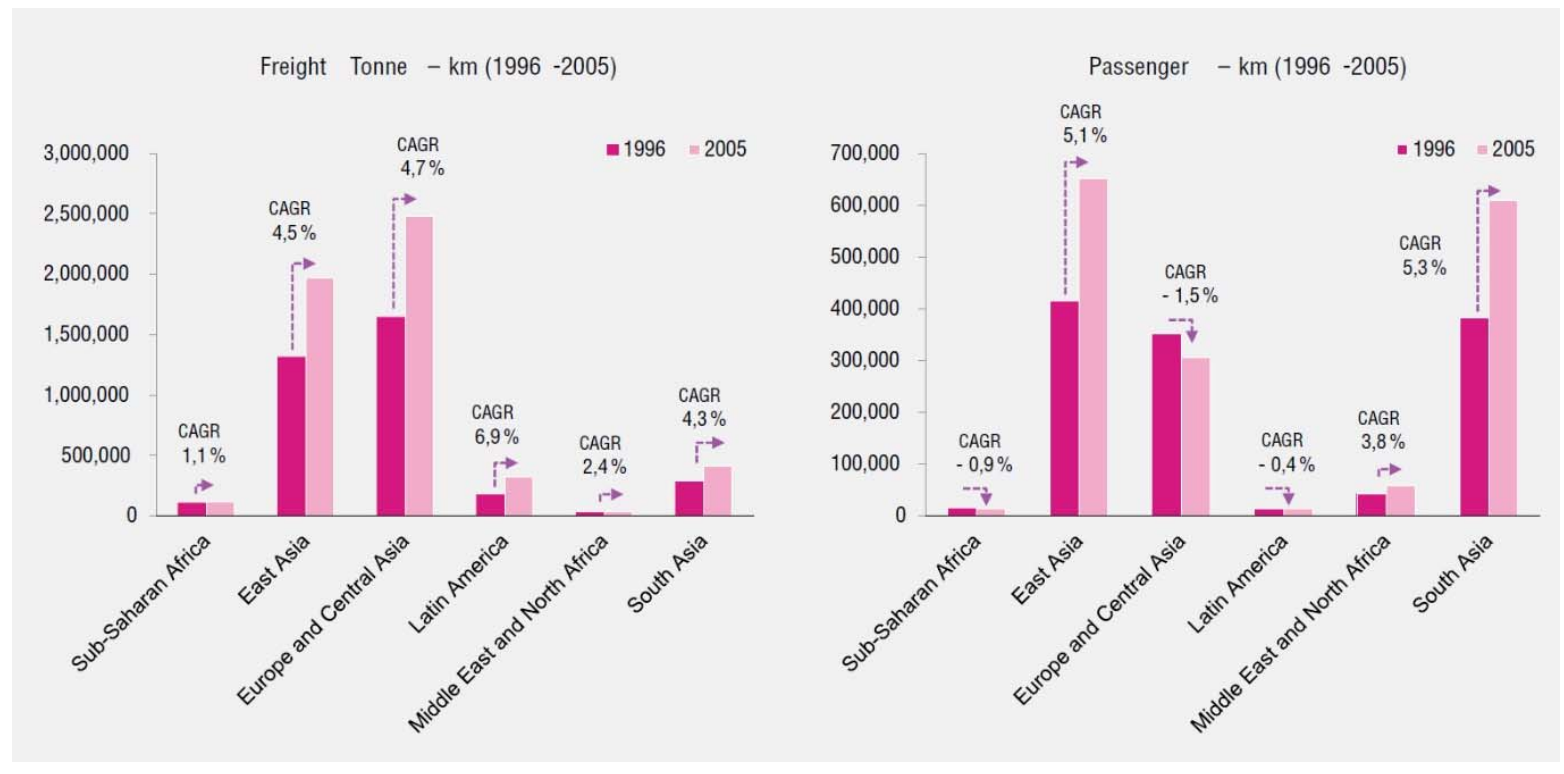

Figure 2. The evolution of the world rail market between 1996 and 2005 [4].

The increase of road transport in low-income countries has been driven by the higher costs of rail operations, maintenance, and renewals, and a lack of strategic planning resulting from political instability and conflicts [3]. In Africa, road transport is responsible for $90 \%$ of passenger traffic and $80 \%$ of the movement of goods [5]. Railways require dedicated corporations to operate passenger 
and freight services. The centralised costs for maintaining and upgrading capital assets create the impression that the railways are too costly to compete with road transport, but rail is considerably cheaper when economies of scale are possible [4].

Despite the financial constraints, many low-income countries in Sub-Saharan Africa and South Asia have followed through and started prioritizing railway infrastructure in their plans for the upcoming decades. The current moment seems appropriate, as most low-income countries are experiencing higher economic growth than the global average, leading to promising prospects [6]. When this growth is combined with an emerging middle class and untapped resources, it is clear that the potential for railway development is timely [6]. In line with this, the African Union has published a vision of a continent-wide rail network to facilitate inter- and intra-regional trade and meet the travel needs of its growing population [7]. In South Asian countries, future goals for railway development are of a similar scale.

Therefore, there seems to exist important gaps between the current status of rail infrastructure, the common vision of regional development, and short-term projects in implementation. While investment in rail infrastructure is seen as an essential feature for the achievement of Sustainable Development Goals, projects need to be chosen carefully, especially in financially constrained countries [5].

\section{Aims, Objectives, Scope, and Limitations}

\subsection{Aims and Objectives}

This paper builds upon the research conducted for the U.K. Department for International Development (DFID), as part of the High-Volume Transport (HVT) project. The project was established to identify key areas for capacity building in order to improve access to more affordable, safer, and lower carbon transport services in low income countries. More specifically, the objectives of the rail sub-theme were to determine the current state of the infrastructure in low-income countries to identify pathways towards regional interoperability goals. Subsequently, the research targeted the gaps in the continental visions with present-day capabilities in order to develop key guidelines for technical development in each region.

\subsection{Scope}

As a starting point, the HVT project focused on low-income countries in Sub-Saharan Africa and South Asia. According to the World Bank [8], low-income countries (LICs) are those where the Gross National Income (GNI) per capita is less than US $\$ 1005$. Lower middle-income economies are those with a GNI per capita between $\$ 1005$ and $\$ 3895$. Besides these countries, the project also included DFID priority projects [9]. Some of these countries are in fact in the lower middle-income bracket, but present similar levels of Human Development Indices (HDI) to their low-income counterparts.

Not all countries that passed the criteria contain rail infrastructure or operate railway services. With these criteria, the initial list of 41 countries was then reduced to the 27 countries, which are listed in Table 1. The rail infrastructure sub-theme then adopted these as the scope of the research project.

Table 1. List of countries contemplated in the project.

\begin{tabular}{cccc}
\hline Afghanistan & Ethiopia & Mali & Sudan \\
Bangladesh & Ghana & Mozambique & Tanzania \\
Benin & Guinea & Myanmar & Togo \\
Burkina Faso & Kenya & Nigeria & Uganda \\
Cote d'Ivoire & Liberia & Pakistan & Zambia \\
Eemocratic Republic of the Congo (DRC) & Madagascar & Senegal & Zimbabwe \\
Eritrea & Malawi & Sierra Leone & \\
\hline
\end{tabular}

Of the 27 countries contemplated, 23 are in Africa and 4 are in South Asia, as illustrated in Figure 3. 

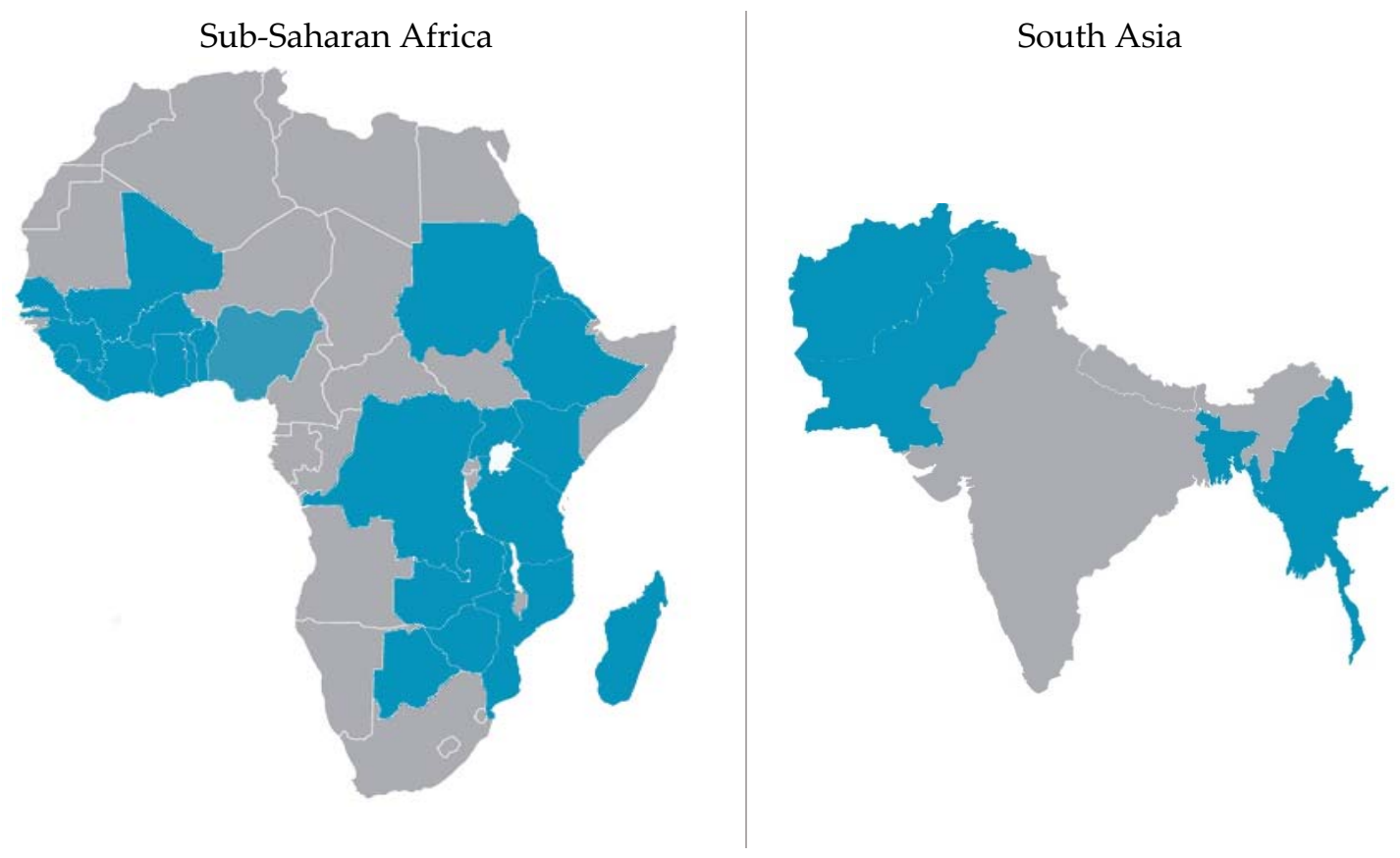

Figure 3. Low-income countries in Sub-Saharan Africa and South Asia contemplated in the project.

\section{Methodology}

This research reviewed the literature on the current state of rail infrastructure to identify development areas that have the greatest potential for increasing future affordability and sustainability of railways in low-income countries (LICs) in Sub-Saharan Africa and South Asia. Findings were also derived from a workshop conducted in Nairobi, Kenya, in November 2018, with key stakeholders from Sub-Saharan African countries.

The review looked at data available from primary and secondary sources. Extensive databases held by organisations such as the World Bank and the International Union of Railways (UIC) were used as the main sources. Secondary sources were reports that provided supporting information $[10,11]$. The availability, age, and robustness of databases found posed a challenge to the systematic process. In South Asia, more up-to-date information was available through reports from governments and international agencies [11-15].

Due to the significant differences in use of rail infrastructure between Sub-Saharan Africa and South Asia, the process of data collection adopted two separate fronts. Breadth of scope was prioritised in this review in order to provide a comprehensive understanding of key areas needing development. Under each front, themes were defined where data was available for both regions. Subsequently, each sub-theme and the list indicators for infrastructure condition and operational performance were defined according to the information available. The process is illustrated in Figure 4.

Information on rail infrastructure and performance in low-income countries was found to be generally fractured and outdated, in accordance with previous works [3,4]. Large discrepancies were found among sources. It was found that the most comprehensive database where indicators are available for most countries analysed stopped being updated between 2005 and 2008 [1,10]. More recent information, where available, was used to calibrate the reliability of sources [11]. Some countries listed infrastructure indicators until 2011, with one listing indicators until 2017 (Democratic Republic of the Congo). In the twelve years separating the data for DRC, no significant changes in indicators were found. 


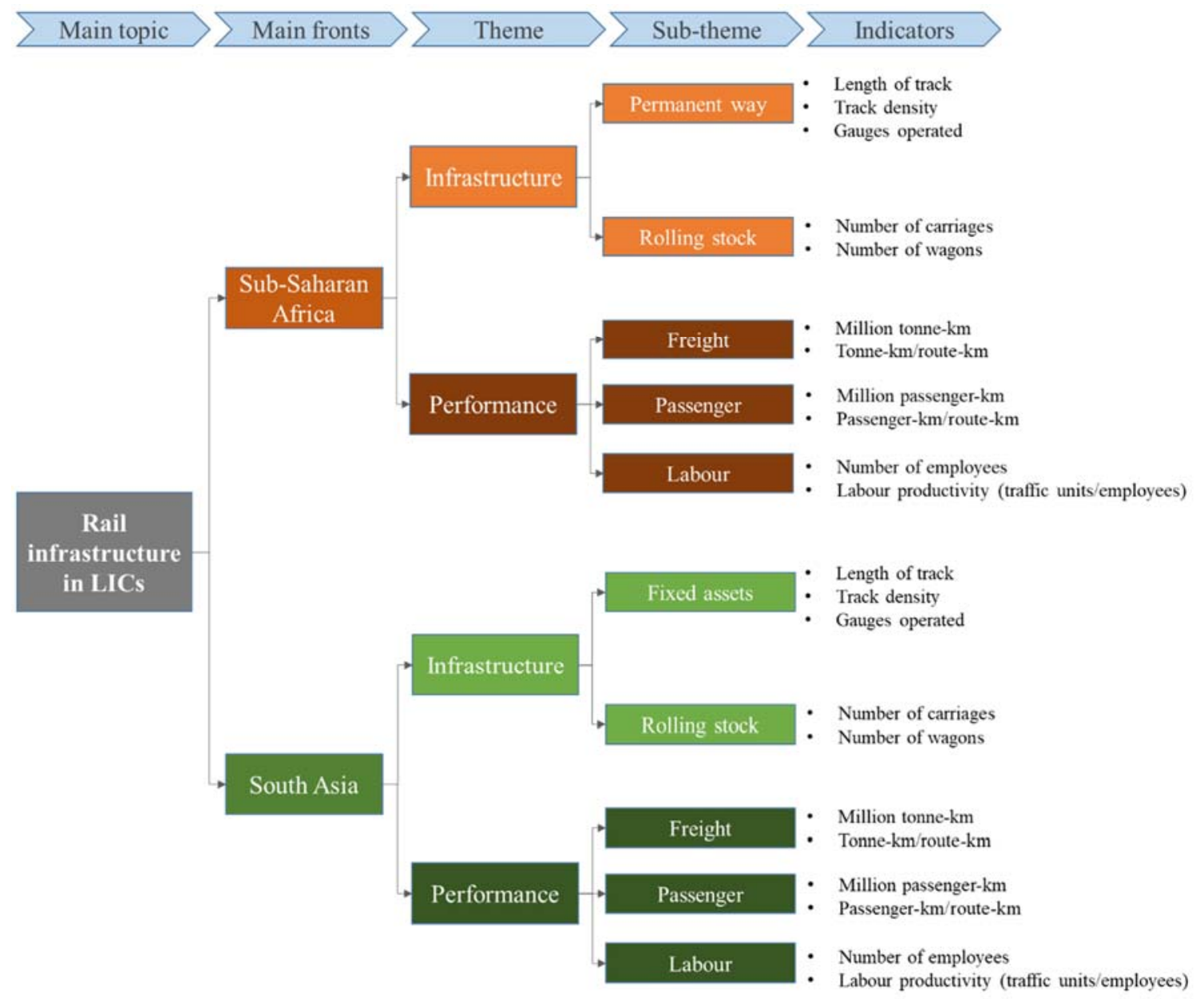

Figure 4. Review process and list of selected indicators.

\section{Current State of Rail Infrastructure in LICs in Sub-Saharan Africa and South Asia}

Please refer to Appendix A for a table comprising the indicators for each country

\subsection{Overview}

While the railways have the potential to be more cost effective where economies of scale permit, low-income countries have struggled to reap the benefits. The general image of railways in low-income countries reflects dilapidated infrastructure, outdated technologies, and low-quality operations in terms of performance and safety. After decades of poor maintenance and little investment, many countries now have major railway sections that are not in operation and require renewal. In general, rail infrastructure in Sub-Saharan African low-income countries seems to be in poorer condition than in South Asia. For instance, 23\% of railways in Benin and 91\% in Uganda are not operational [3]. In other countries, many parts of the rail network are idle, such as $60 \%$ of the network in Ghana [3].

The limited length and quality of railway routes has particularly impacted the regional connectivity of landlocked countries and imposes higher freight costs for two reasons. Firstly, the limited size and quality of the network reduces the freight volumes that the line can transport, negatively affecting labour productivity and efficiency. Secondly, the limited reach of rail routes means that freight has to be transferred to road transport to reach most destinations, which increases the costs compared to road-only transport. Thirdly, the variety of different gauges encountered within the regions prevents a steady traffic flow on the railway networks. It is not surprising that transport costs in LICs in Sub-Saharan Africa are the highest worldwide, with freight charges $20 \%$ higher than in low-income countries in other regions [16]. 
For many of these countries, the length of railway infrastructure has an impact on the potential to exploit their substantial deposits of natural resources. Furthermore, rail infrastructure in many LICs dates back to colonial times and much of the network has not been upgraded since. Each nation post-independence retained the track gauges that had been selected by their colonisers $[6,10]$.

Track densities in LICs are generally lower than the global average. The exceptions are small countries, such as Bangladesh, and countries with very small networks, such as Afghanistan. In LICs in Sub-Saharan Africa (SSA), average track density is even lower at $2.76 \mathrm{~km}$ per $1000 \mathrm{~km}^{2}$, while LICs in South Asia (SA) are served by a relatively higher density of $7.8 \mathrm{~km}$ of track per $1000 \mathrm{~km}^{2}$ [10]. There are expected variations where either area or population is significantly high, yet LICs in both regions fare poorly when compared to countries with robust rail traffic. For instance, Germany has $121 \mathrm{~km}$ of track per $1000 \mathrm{~km}^{2}$, which possibly explains why its railways carry $43 \%$ of the country's freight [17].

\subsection{Sub-Saharan Africa}

\subsubsection{Infrastructure}

In Sub-Saharan Africa (SSA), rail infrastructure is predominantly used to transport freight (Figure 5). This can be partly explained by the vast reserves of minerals and bulk commodities in many countries in the region. Most railways connect major ports to large cities and mining areas because $90 \%$ of African imports and exports are transported by sea $[4,18]$. However, the movement of people and goods through the continent is limited because there is little connectivity between railway networks. Only a few lines cross borders, such as the Tanzania-Zambia Railway Authority (TAZARA) connecting Tanzania and Zambia, and Sitarail between Burkina Faso and Cote d'Ivoire. Interoperability is also constrained. Several countries operate different track gauges that range from $600 \mathrm{~mm}$ to standard $(1435 \mathrm{~mm})$. Cape gauge lines of $1067 \mathrm{~mm}$ predominate, especially in the south, followed by metre gauge $(1000 \mathrm{~mm})$ lines and standard gauge $(1435 \mathrm{~mm})$, which are more recently built [10]. Efforts in building new standard gauge tracks seem to overshadow interest in existing infrastructure.

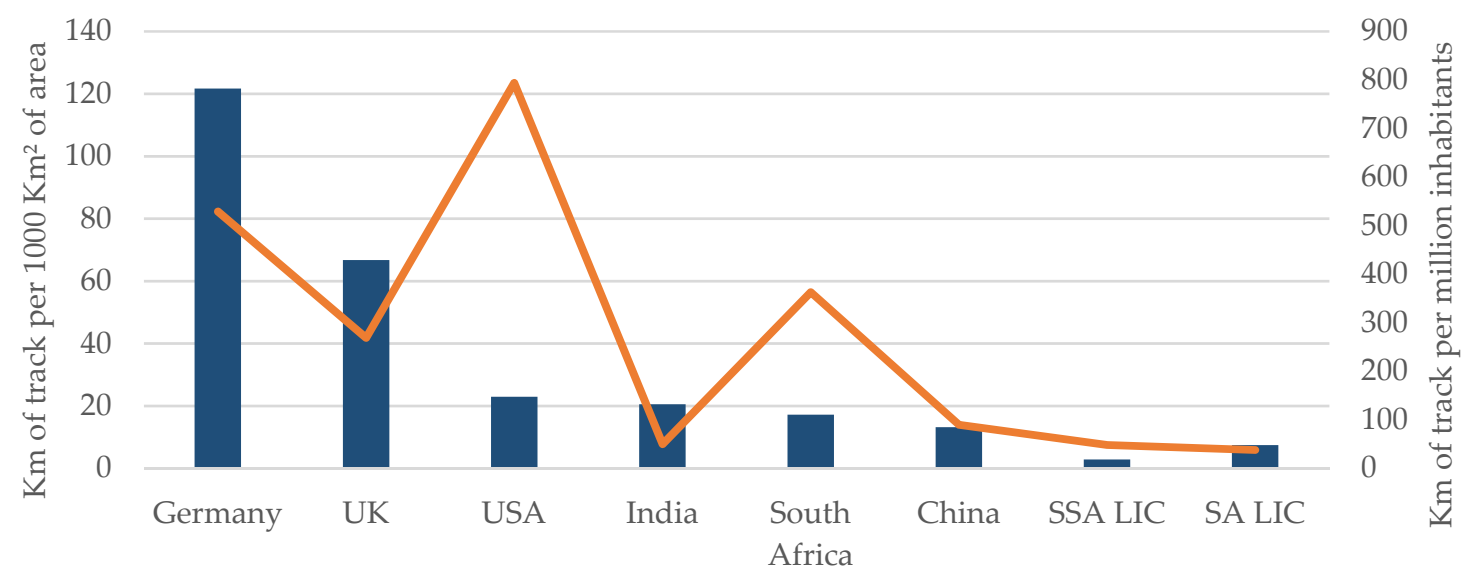

Track density $\left(\mathrm{km} / 1000 \mathrm{~km}^{2}\right) \quad$ Km of track per million inhabitants

Figure 5. Track density in Sub-Saharan African (SSA) and South Asian (SA) low-income countries (LIC) compared to middle and high income countries $[1,8]$.

Although the commonly used narrow gauge tracks are said to marginally limit the loading gauge of trains, greater loads are carried on South African Cape gauge tracks than on standard gauges in the United Kingdom [10]. However, smaller gauges tend to be associated with smaller curve radii, so rolling stock design and performance are crucial. The main concern with narrow gauges is the lateral oscillation (hunting) because of short-wheelbase bogies. The greater lateral oscillation of narrow gauges impacts passenger comfort, yet there are measures to address this issue, such as improving 
suspension systems, lowering the centre of gravity of the wagon, or adjusting the lateral forces on the tracks [19].

Figure 6 illustrates the greater connectivity found in the southern region of the continent, where countries connect to the more developed network in South Africa. A metre gauge line from Mombasa in Kenya to Dar es Salaam in Tanzania connects the East Africa region. Until recently, little has been done to improve the connectivity and interoperability of rail infrastructure in LICs in Sub-Saharan Africa. Early attempts with concessionary frameworks transferred the responsibility of infrastructure maintenance and renewal to operators. Following that, the lines were not extended and connectivity remained very limited [6].

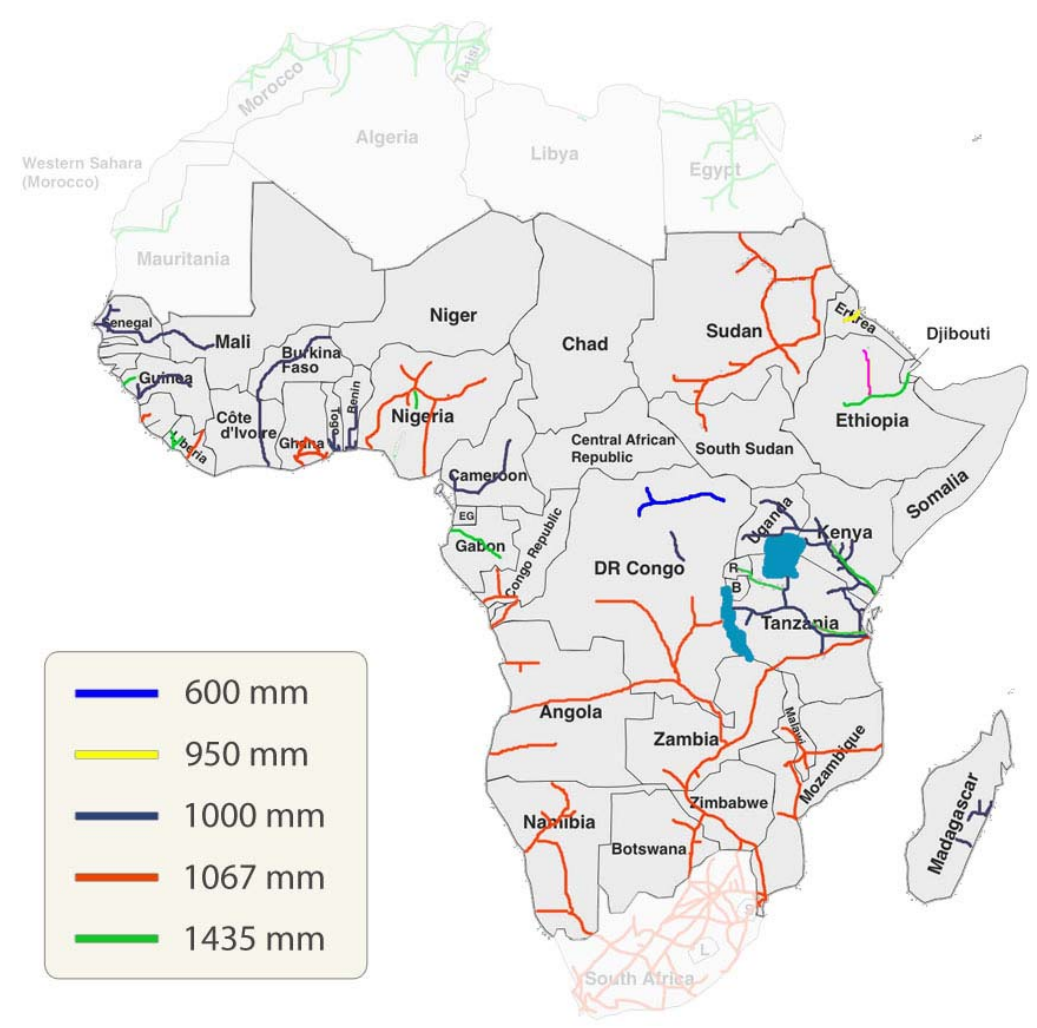

Figure 6. Track gauges operated in Sub-Saharan Africa (adapted from creative commons media Attribution-ShareAlike 4.0 International Public License).

Literature shows that not only track density but also track quality is below international standards in Sub-Saharan Africa. Many railway assets in LICs are more than 100 years old, and thus the quality of track materials is considerably outdated [6]. In much of Sub-Saharan Africa, the original rail tracks are ballasted but have not been appropriately or regularly maintained. The combination of asset age and inadequate track maintenance and tamping has severely affected the operational performance of railways in the region. Firstly, the maximum axle load that the railway track structure can withstand in Sub-Saharan Africa is approximately 15 tonnes [3]. In comparison, European standards for axle loads are greater than 25 tonnes [20]. The poor track quality affects the maximum speed achievable. In 2009, freight trains in Sub-Saharan Africa reached only an average speed of $18 \mathrm{~km} / \mathrm{h}$ [3].

Almost all lines are single track. Data on double track sections or passing loops were not available for a more detailed investigation. Sidings and platforms are outdated and date back to the original lines first built. In many cases, signaling on networks still relies mostly on manual systems, whether with mechanical signals or manual train orders [3]. Manual systems are adequate for the very low traffic currently achieved on most lines, but human error often creates safety problems. For traffic to be increased in a safely manner, signaling systems may prove to be a barrier that needs to be overcome. 
None of the original lines are electrified [6]. Electrified lines are only available on a few routes built in recent projects, but these present challenges. The electrical grid in many low-income countries in Sub-Saharan Africa is not robust enough to accommodate an electrified railway network. In Ethiopia, for example, a separate grid was built to cater for the large amount of power required to run electric trains [21]. Where electrically powered signaling is installed, often it cannot be used because of short circuits, no electrical power, and degraded cable networks that are susceptible to cable theft. Telephone exchanges in many railways are obsolete, with limited capacity and with spare parts being virtually impossible to obtain [3].

\subsubsection{Operational Performance}

Railway traffic consists mainly of freight services in low-income countries in Sub-Saharan Africa. The movement of goods accounts for almost $90 \%$ of the traffic in the region. This can be explained by the fact that it is more difficult to recover the costs of passenger operations without subsidies, and with limited track availability, more cost-effective choices have to be made.

The combination of low maximum axle loads and speed limits within limited routes has a significant impact on traffic volumes achievable in LICs in Sub-Saharan Africa. Traffic volumes are an important measure of the sustainability and affordability of rail operations because they highlight infrastructure usage. Higher volumes generate economies of scale in the costs of infrastructure maintenance and improvements, which in turn increase the competitiveness of rail transport against other modes.

With the exception of Guinea, where private mining companies extensively use their own railway lines, all LICs show traffic densities below or around 1 million traffic units (tonne-km plus passenger-km) per route-km (Figure 7). Data for Eritrea, Liberia, and Sierra Leone were not available. In contrast, railway networks in the United Kingdom, France, and Germany operate around 4.5 million units per route-km. Global leaders in traffic volumes such as Russia, the United States, and China reach densities up to 40 million units per route-km (Figure 8) [1,17,22].

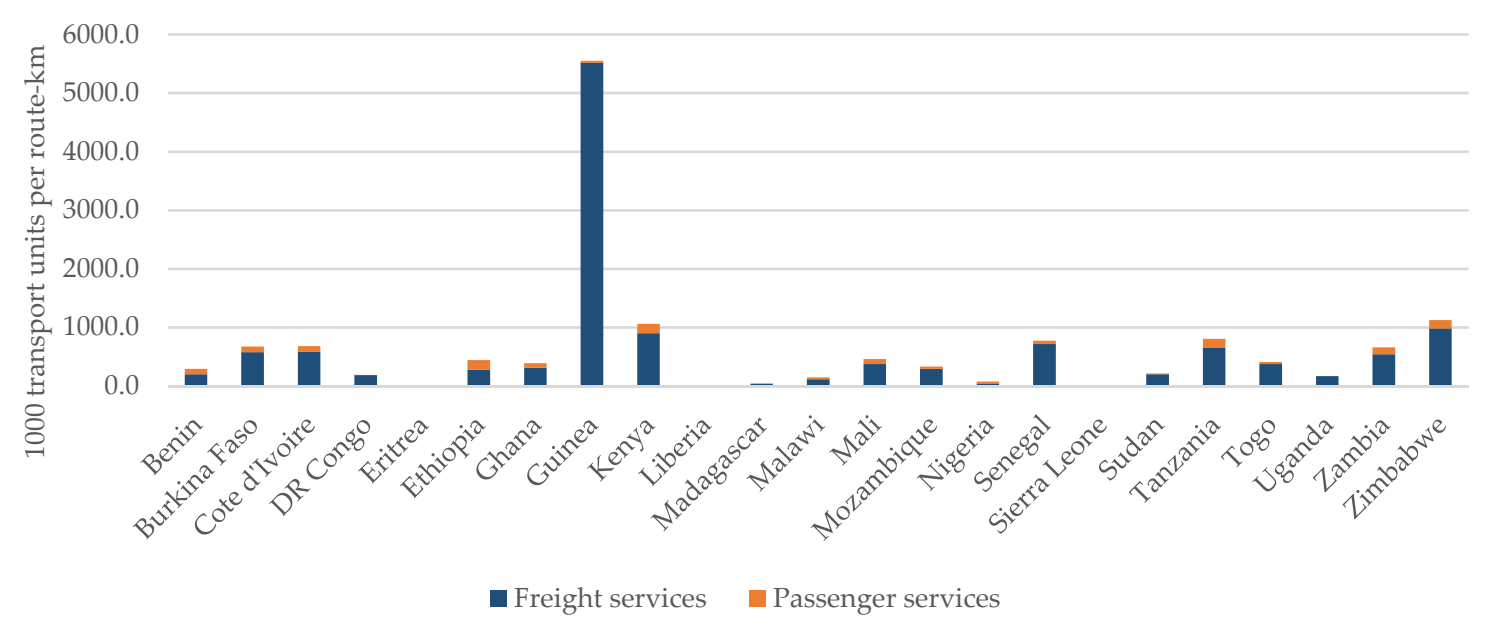

Figure 7. Rail traffic density in SSA LICs [10]. 


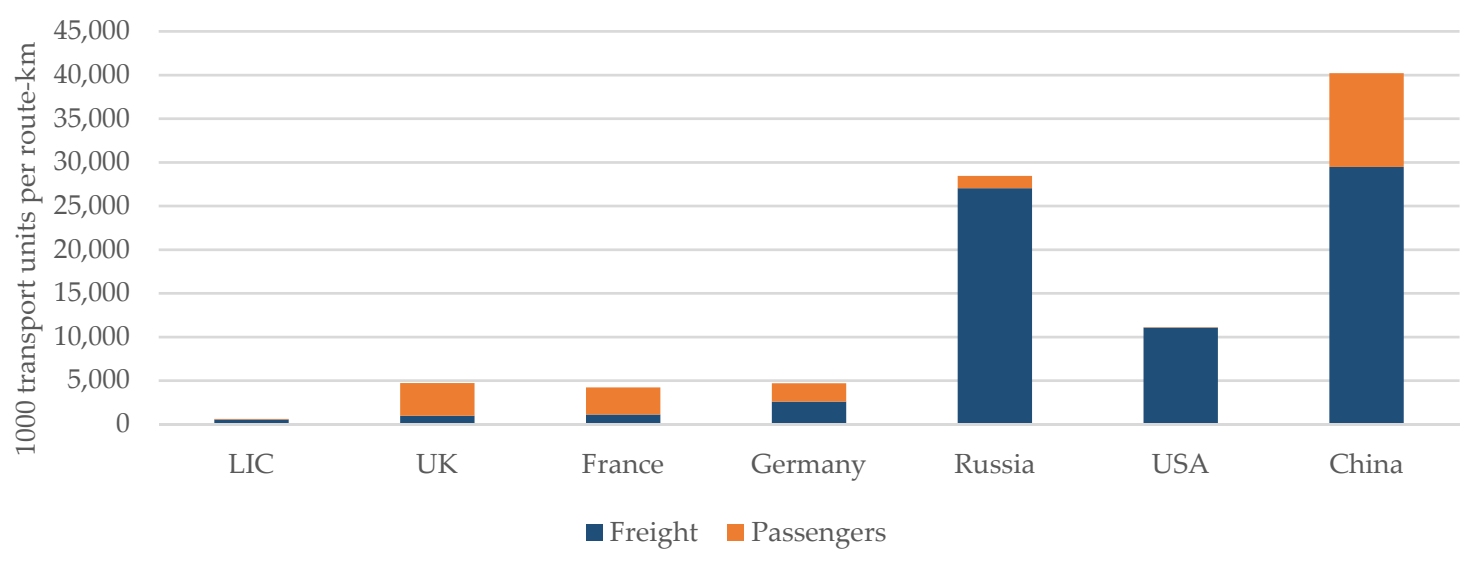

Figure 8. Rail traffic density in SSA LICs compared with high income countries and global leaders [1,10].

Due to the low volumes achieved, labour productivity is significantly lower in most LICs in Sub-Saharan Africa than in developed nations. On average, employees in the United Kingdom produce four-times more traffic units per employee than SSA LICs. In a more extreme comparison, while an average employee in LICs in Sub-Saharan Africa produces 150,000 traffic units per year, a U.S. employee produces 14.2 million (Figure 9) [8,22]. Under these circumstances, fixed costs are spread over fewer traffic units, which in turn become expensive in comparison to other transport modes. In exchange, that leads to a vicious cycle where higher unit costs lead to lower demand, which affects the unit costs and return. The exceptions in the region are Burkina Faso, Senegal, and Zambia, which reach approximately 500,000 units per employee and are close to the productivity of German railways [10]. No data was found for Guinea.

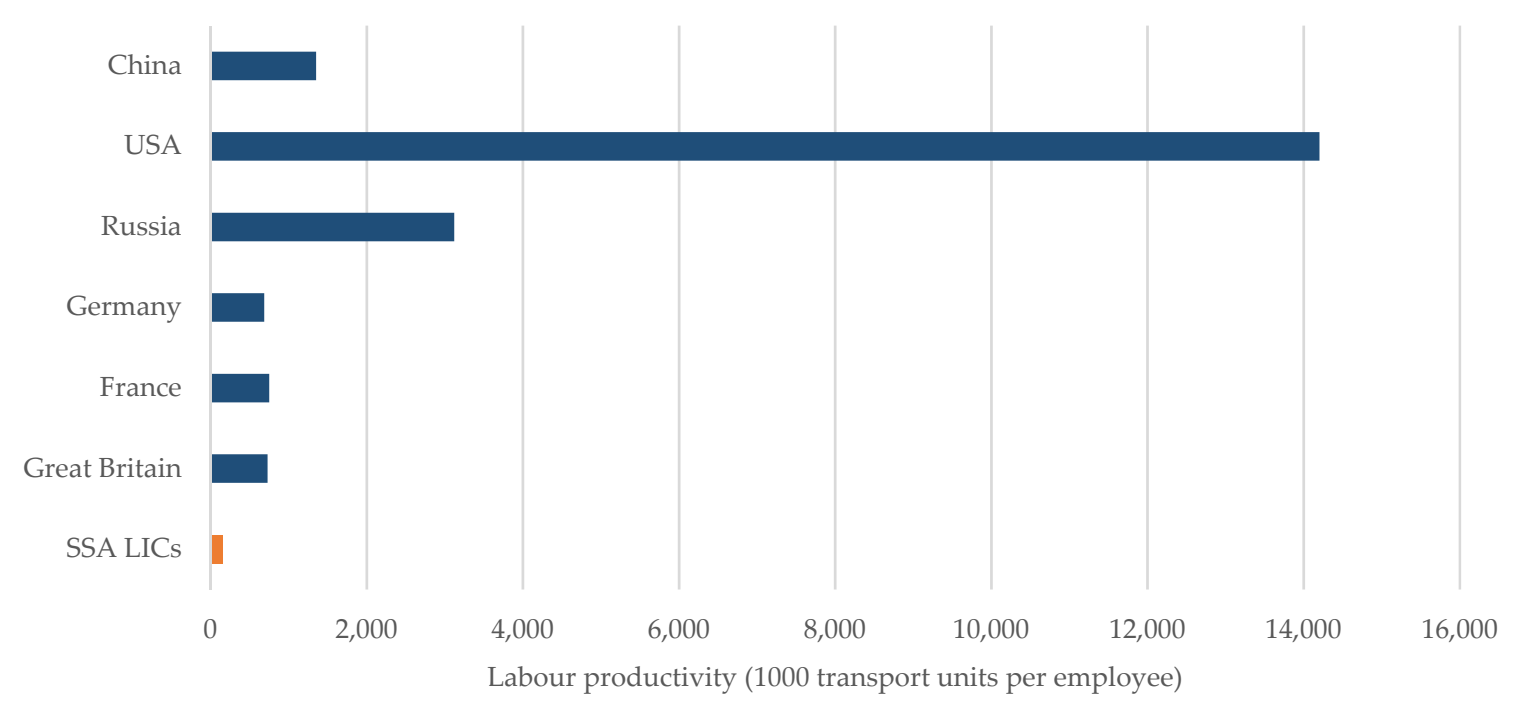

Figure 9. Comparison of labour productivity between SSA LICs and selected countries [10,22].

Safety on railways in low-income countries has been a matter of significant concern. There is very little data on safety records, as well as unclear standards and compliance, and the issue has been raised in the literature [3-5]. In addition, safety was the most mentioned aspect during the workshop with key stakeholders in Nairobi. Respondents listed trespassing, derailments, and theft of infrastructure as the main problems faced in the region. From the data available, safety records in LICs in Sub-Saharan Africa are significantly worse when compared to other countries [11].

Sample safety records were found for DR Congo (2015), Cote d'Ivoire (2002), Kenya (2002), and Nigeria (2003), and used to infer a comparison against more developed economies [11]. With 
0.545 accidents for every million traffic units, DR Congo had an accident rate 545-times higher than Germany or Great Britain (0.001 accidents per million traffic units), and 32-times the average in the developing world $[11,13]$. Other LICs performed better but still experienced over 100 more accidents than the two European counterparts, as shown in Table 2.

Table 2. Safety record of sample SSA LICs compared to Germany and the United Kingdom [11,22].

\begin{tabular}{cccc}
\hline Country & Traffic Units (million) & Accidents & Accidents per Million Traffic Units \\
\hline DR Congo (2015) & 697 & 380 & 0.545 \\
Cote d'Ivoire (2002) & 436 & 91 & 0.209 \\
Nigeria (2003) & 268 & 108 & 0.403 \\
Kenya (2002) & 2191 & 249 & 0.114 \\
Germany & 208,262 & 346 & 0.0016 \\
Great Britain & 68,912 & 71 & 0.0010 \\
\hline
\end{tabular}

\subsection{South Asia}

\subsubsection{Infrastructure}

There are significant differences between railway usage in South Asian LICs and those in Sub-Saharan Africa. Railway systems in South Asia's LICs are mostly used for passenger transport. Since the railways are owned and operated by the government in all countries analysed, services are heavily subsidised for social reasons. Railway lines connect major cities in commuting networks across regions and sometimes between countries.

Possibly due to closer geographical proximity and a more common colonial influence, track gauges in South Asia are more homogenous than in Sub-Saharan Africa (see Figure 10). Countries bordering India have adopted mainly the same broad gauge $(1676 \mathrm{~mm})$, which assists with connectivity and interoperability. Nepal has broad gauge track infrastructure but has not operated railway services since 2008. East of India, trains in Myanmar and east Bangladesh run on meter gauge tracks $(1000 \mathrm{~mm})$. In Pakistan and west Bangladesh, broad gauge tracks are the standards [23]. Further west, a short line in Afghanistan runs on Soviet gauge $(1520 \mathrm{~mm})$. Bangladesh also has $365 \mathrm{~km}$ of dual gauge track (metre gauge and broad gauge) connecting the broad gauge network in the west to the meter gauge network in the east [12,24]. Pakistan runs a short $312 \mathrm{~km}$ metre gauge line [15].

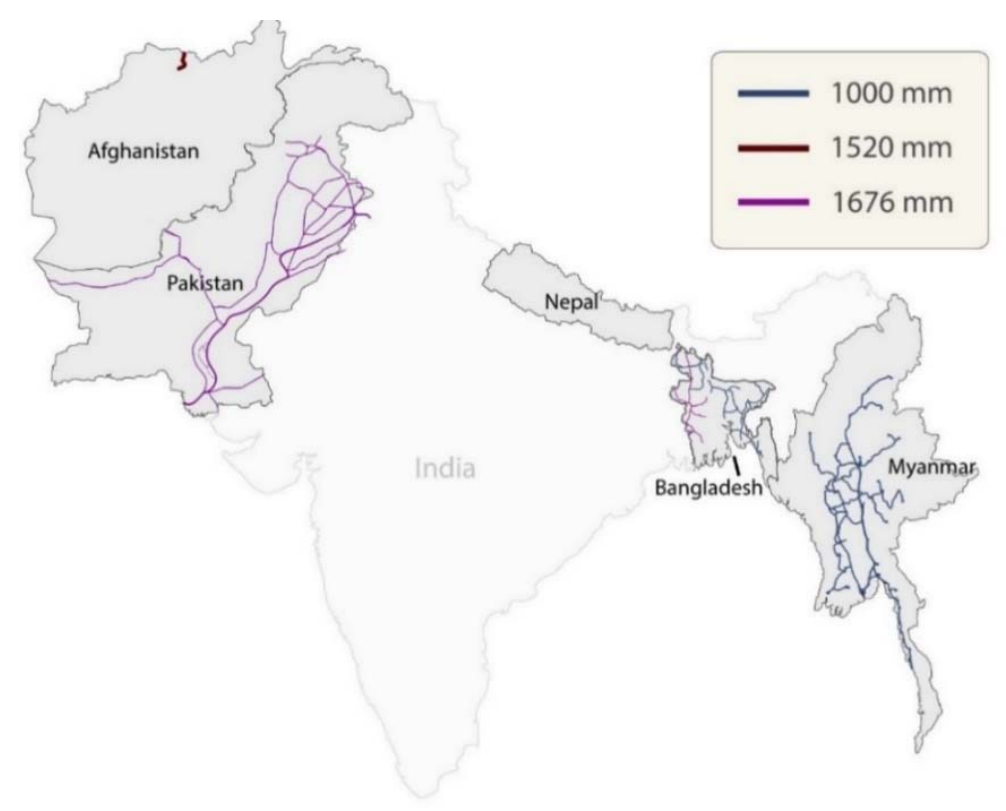

Figure 10. Illustration of track gauges in use in South Asia (based on previous work [10-13]). 
With a total of $7.8 \mathrm{~km}$ per $1000 \mathrm{~km}^{2}$, LICs in South Asia are almost three times more densely crossed by railway lines than low-income countries in Sub-Saharan Africa [10,22]. Bangladesh has more railway tracks per area than Pakistan and Myanmar but a lower track density per head of population. Despite the higher track density, age of assets and infrastructure quality in South Asian LICs are a similar issue to those found in Sub-Saharan Africa. In all four countries studied, most lines are single track. In Pakistan, only approximately $10 \%$ of the track is double track.

Track quality varies according to country, and has an important impact on operational performance. Poor condition of the track infrastructure, which includes aspects such as track alignment, ballast condition, and the presence of cracks on the rail surface, not only limits the maximum load and speed that can be safely achieved but also increases the risk of derailment. For instance, railway infrastructure in Myanmar has an axle load limit of only 12.5 tonnes [14]. Moreover, the infrastructure condition in the country limits the maximum speeds of freight trains to $48 \mathrm{~km} / \mathrm{h}$ and passenger trains to $60 \mathrm{~km} / \mathrm{h}$. Pakistan and Bangladesh have upgraded rail tracks to support 22.5 tonnes per axle in certain sections. In other sections, axle load is limited to 17.87 tonnes [23]. The variance in track quality is problematic in two ways. The lower threshold limits rolling stock loads and wastes the investments in the sections with better track quality, while there is a risk that rolling stock loads match the improved sections and present a risk of overloading the track. Available traffic speeds have not improved. As an example, the average speed of freight trains in Bangladesh is only $18.5 \mathrm{~km} / \mathrm{h}$ [12].

In the region, none of the lines are electrified and signaling is still mainly manual. Ahmed et al. [24] have listed the outdated systems as a threat to safe and efficient train operations in Bangladesh. In Myanmar, contracts to upgrade signaling to electronic systems have been signed recently but are still not available [25].

\subsubsection{Operational Performance}

Traffic densities in South Asia are considerably higher than in LICs in Sub-Saharan Africa. Crowded passenger volumes make traffic densities (1000 traffic units per route-km) in Pakistan and Bangladesh comparable to high-income European countries, such as Great Britain, France, and Germany, but still far from world leaders, such as Russia and China (Figure 11). According to recent data, Bangladesh and Pakistan operated approximately 3.0 and 3.6 million traffic units per route-km, respectively [12,15]. Myanmar has a traffic density below 1 million units per route- $\mathrm{km}$, and therefore is considered a low volume network similar to most low-income countries in Sub-Saharan Africa [14]. Contrary to the African continent, only a small proportion of total rail traffic in South Asian LICs is dedicated to freight. Passenger services account for $80 \%$ of the total traffic in the region [10]. No traffic data was available for the Afghan line, which operates only freight services to Uzbekistan.

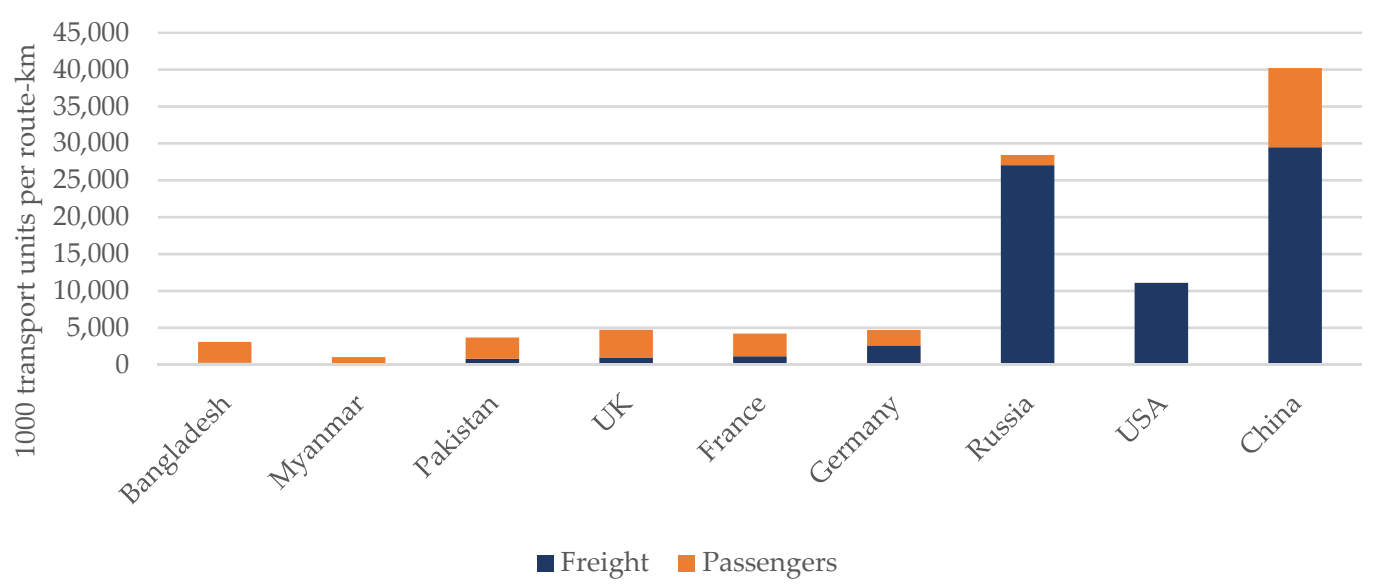

Figure 11. Traffic density of South Asian LDCs compared with high income countries and world leaders [9-13,15]. 
While there are clear differences in traffic densities between Myanmar and the other two countries (Bangladesh and Pakistan), the gap in labour productivity seems to be less wide. The three countries are more productive than the majority of Sub-Saharan African LICs, but the average output per employee is still half of the German counterpart (Figure 12). Bangladesh and Pakistan show similar output levels at 343,000 and 389,000 traffic units per employee [12,14]. Myanmar achieves lower productivity levels at 213,000 traffic units per employee, which can possibly be linked to the lower speeds and loads available on its network [13]. In railways where passenger services are dominant, as in South Asian LICs, operations are usually subsidised because they are unlikely to break even. Low productivity adds to the issue by increasing the operational expenditure per transport unit [3].

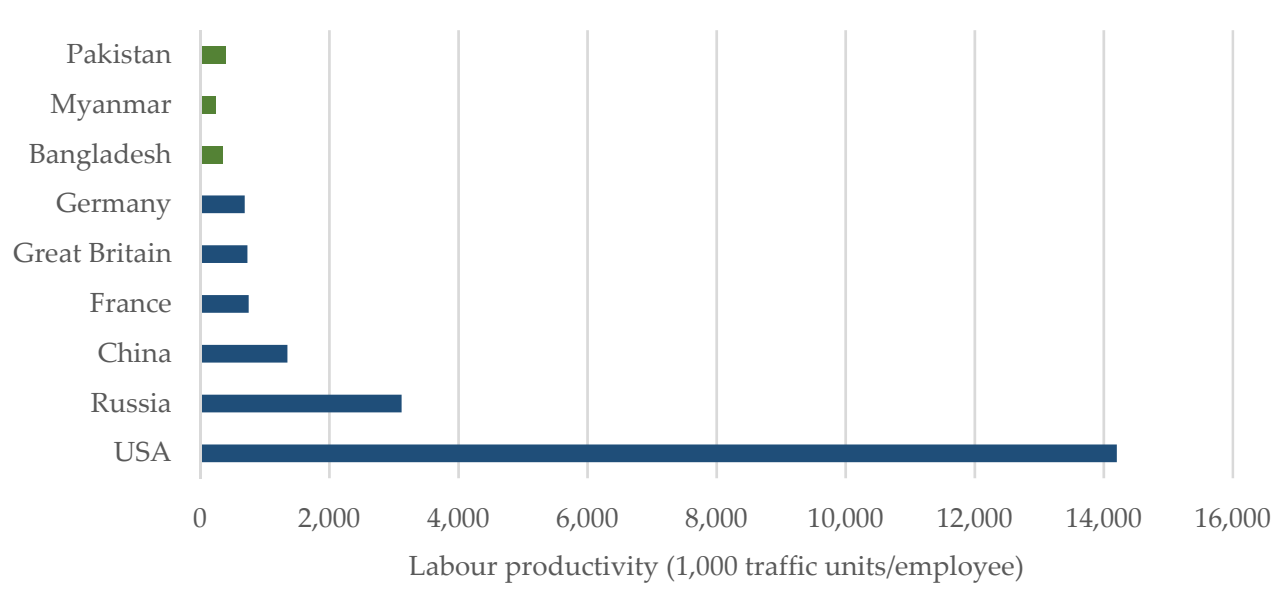

Figure 12. Comparison of labour productivity between SA LICs and selected countries $[11-15,17]$.

Safety records in South Asian LICs are better than those found in low-income countries in Sub-Saharan Africa (Table 3). Bangladesh reported 707 accidents in 2005, which translates to 0.142 accidents per million traffic units in that year [11]. Pakistan has reported better records recently, with 139 accidents over a much greater volume, resulting in an accident rate of 0.004 incidents per million traffic units [15]. This performance positions Pakistan much closer to the rates found in other LICs. Safety records in Bangladesh still reflect similar values to LICs [12].

Table 3. Safety record of SA LICs compared to Germany and the United Kingdom [12-15,17].

\begin{tabular}{cccc}
\hline Country & Traffic Units (million) & Accidents & Accidents per Million Traffic Units \\
\hline Bangladesh (2005) & 4981 & 707 & 0.142 \\
Myanmar (2013) & 4261 & 500 & 0.117 \\
Pakistan (2017) & 28,549 & 139 & 0.004 \\
Germany & 208,262 & 346 & 0.0016 \\
Great Britain & 68,912 & 71 & 0.0010 \\
\hline
\end{tabular}

Secondary data from the Asian Development Bank (ADB) estimate that Myanmar Railways experienced around 500 accidents per year, which results in a rate of 0.117 accidents per million traffic units [13]. The same document states the accident rate as 0.852 per million traffic units, which highlights the fragmented nature of datasets. In the country, most accidents are derailments caused by poor track quality [13].

\section{Recent Sino-African and Sino-Asian Projects}

The review of rail infrastructure and operations in low-income countries in Sub-Saharan Africa and South Asia has highlighted the disparity between the current conditions and national and regional visions for the future. With financial challenges in working towards these goals, various 
low-income countries have recently signed resource-for-infrastructure agreements, mostly with China, to replace dilapidated infrastructure with new lines using modern technologies [16]. From the literature, Sino-African projects exceed those found in South Asia. This may be explained by the large investments from the ADB in the region to develop a Trans-Asian Railway network [26]. Conversely, projects in Sub-Saharan Africa seem to be conducted on an ad hoc basis.

Since its beginning in 2006, Sino-African trade volumes grew rapidly to reach more than US $\$ 200$ billion in 2013 [16]. These resource-for-infrastructure investments include several railway projects across the continent, with some examples listed in Table 4. Most projects consist of single track, non-electrified, standard gauge lines [18,21,27-29]. Lines are built with freight and passenger services in mind and permit an average maximum speed between $100 \mathrm{~km} / \mathrm{h}$ and $120 \mathrm{~km} / \mathrm{h}$ [18,21,27-29]. There are exceptions to these standards: (1) the Addis Ababa-Djibouti line, which is electrified and includes $151 \mathrm{~km}$ of double tracks; (2) the Mali-Senegal line, which is a renovation of the existing infrastructure; and (3) the Abuja-Kaduna section of the Lagos-Kano line, which is double-track and will permit speeds of up to $250 \mathrm{~km} / \mathrm{h}[30]$.

Table 4. Sino-African railway development projects [18,21,27-30].

\begin{tabular}{clcc}
\hline Country & \multicolumn{1}{c}{ Project } & Length & Cost (in US\$) \\
\hline Chad & Chad Railways [27] & $1364 \mathrm{~km}$ & 5.6 billion \\
Ethiopia-Djibouti & Addis Ababa-Djibouti line [21] & $751 \mathrm{~km}$ & 4 billion \\
Mali & Mali-Guinea Railway line [28] & $900 \mathrm{~km}$ & 11 billion \\
& Mali-Senegal Railway [18] & $1286 \mathrm{~km}$ & 11.1 billion \\
Nigeria & Lagos-Calabar line [29] & $1400 \mathrm{~km}$ & 8.3 billion \\
Kenya & Lagos-Kano line [30] & $1124 \mathrm{~km}$ & 4 billion \\
\hline
\end{tabular}

In South Asia, such projects are not as numerous. In Bangladesh, work has started on the Padma Bridge Rail Link, a $225 \mathrm{~km}$ project connecting regions to the port of Payra, at a total cost of the project expected to be US\$3.14 billion with a loan of $80 \%$ of the amount [31]. Pakistan signed with China a US $\$ 8.2$ billion overall investment in railways in Pakistan, including the renewal of broad-gauge tracks and the acquisition of rolling stock. It has since, however, been reduced by US\$2 billion due to concerns over the costs of the loans [32].

At a first glimpse, these projects are reshaping the capacity of existing routes. For instance, the line connecting Addis Ababa to Djibouti has reduced the journey time between Djibouti and the dry port of Mojo in Ethiopia from $84 \mathrm{~h}$ to 10-15 h [21]. Similarly, the Standard Gauge Railway has reduced journey times between the port of Mombasa and the capital Nairobi to less than $5 \mathrm{~h}$. In Nigeria, these projects are expected to provide a long-awaited expansion to reduce congestion on the country's damaged roads [33].

However, there is significant concern over the sustainability of these projects. From an economic perspective, concern is increasing that these large loans will tie low-income countries to a long-term dependency on China rather than promoting internal development [16]. These concerns have some support in the case of Sri Lanka, which handed over control of one of its deep-sea ports to ease its debt with China [34]. Moreover, the cost-effectiveness of such large-scale projects has been questioned. For instance, the Mombasa-Nairobi line in Kenya is reported to have cost close to three times the international standard and four times the original estimate [35].

From a technical standpoint, systems have been developed only within the national context, with little attention to compatibility and standardisation [6,36]. Rahmatullah [36] adds that regional rail use is likely to be constrained by differences in track gauge, track structure, signaling systems, and incompatible rolling stock. Delelegn [21] highlighted that lines within Ethiopia run on different signaling systems because they were built by different companies. Stakeholders at the Nairobi workshop shared similar concerns about the link between new rail infrastructure and wider development regional plans, where projects are not standardised with regard to maximum axle loads and speeds, and control 
and communication systems to be used in different sections. It was also highlighted that national masterplans were not available and very few documents were digitalised for common access.

Moreover, it seems that recent investments are not entirely aligned with the current gaps in capability. Technical decisions on new projects are being driven by external forces, including international suppliers and foreign governments, rather than following regional plans with a holistic perspective. This has resulted in investments in solutions that do not match the requirements of the specific context and development trajectory of low-income countries. For example, electrification is still not possible in many countries, as the national electricity grids are insufficient to support railway operations. When electrified lines were built in Ethiopia, a new grid had to be added to the project [21]. Furthermore, expensive and highly sophisticated complex systems have been specified where they are not required, as in the example of the deployment of advanced ERTMS Level 3 (European Rail Traffic Management System Level 3) technologies in Zambia, where traffic volumes are less than 1.5 million traffic units per year [37].

There are clear discrepancies in future goals and current actions. Since there is no established technology roadmap to lead national development towards a common goal, countries are buying off-the-shelf technologies that are too expensive for the near future traffic projected. In doing so, their pathway to development is likely to only follow the steps of developed countries decades ago and remain outdated in the long-term. Little attention has been given to the specific context of the regions and their needs for fit-for-purpose solutions that can leapfrog previous development curves and create fit-for-purpose solutions.

If these problems are left unaddressed, there is significant potential for scarcely available money to be wasted, and for new railway systems to underperform and lose money. Such an outcome is likely to slow the rate of development of railways in low-income countries and lead to less efficient and more environmentally damaging solutions being deployed in the future.

Therefore, it is imperative that scarcely available investments are made consistently and coherently in order to follow a pathway towards continental future goals. Experience in developed regions shows that technical strategies are important studies that can identify common capabilities and produce context-specific and fit-for-purpose technology roadmaps that connect future visions to current levels of development.

\section{Technical Strategies in Europe}

In 1995, the European Union had a similar vision to restructure the rail transport market and strengthen the position of the rail industry in relation to other transport modes [38]. Infrastructure at that point was in a much better condition than currently found in LICs in Sub-Saharan Africa and South Asia, yet there was a need for harmonised development to fulfil the goals of a continent-wide network. This implied opening-up of the rail transport market to competition, improving interoperability and safety of national networks, as well as developing better rail infrastructure [36]. These three main areas-crucial to the development of a strong and competitive rail transport industry-are no different from what is required to enable low-income countries to provide an efficient, reliable, and safe alternative mode of transport for its citizens.

To achieve these goals, the European Union started developing technical strategies to connect future visions to tangible development programs. The first edition was published in 2008 with the purpose of "foreseeing the kind of railway that the rail industry is capable of supplying in response to European and national needs and affordability criteria, to assess whether this railway can be delivered through 'natural' incremental change mechanisms, or whether some planned strategic changes are required" [39].

Technical strategies are roadmaps to connect the present state to the future goals of systems because the gaps between both are usually of considerable magnitude. In this, the complex context and the uncertainty that surrounds development require coordinated actions to achieve a common 
goal. Moreover, technical strategies are incremental, as new versions build on achievements of the previous plans.

For instance, the technical strategy in 2008 focused on interoperability and efficient and border-free acceptance [39]. Ten years later, the 2019 version of the European Technical Strategy envisioned further advancements, such as demand-responsive services, low-carbon solutions, and greater safety than any other transport mode [40].

The jump in capabilities illustrates the active role that technical strategies can have in linking outputs and outcomes. In 2014, the European Commission established a platform for coordinating research activities in the railway sector under the name of Shift2Rail [41]. Since then, efforts to support a Single European Railway Area have been carried out in the form of joint undertakings, where public-private partnerships conduct research and development projects. The research programs are defined by the Shift2Rail commission, in the face of the overarching regional goals of the European Commission, as well as the recent technological developments in the various transport sectors. This combination of top-down and bottom-up perspective ensures that local capability is improved in accordance with regional visions.

In the United Kingdom, similar work has been carried out with the Railway Technical Strategy (RTS). The RTS aims to support strategic planning processes of railways while guiding stakeholders on the deployment of technologies to steer the future of the railway industry's technical direction. The strategy's time frame is 30 years, balancing between the lifespan of rolling stock, which ranges from between 25 and 40 years, and stations' and assets' lifespans of 100 years or more. The RTS has six main themes, namely control, command and communication; energy; infrastructure; rolling stock; information; and customer experience. These themes reflect on strategies that address technical and operational domains within the rail industry.

To connect the vision to achievable milestones, the RTS makes use of Capability Delivery Plans (CDP). These are developed for the delivery of a holistic set of key capabilities that can achieve strategic goals while ensuring a sustainable market. The first edition in 2012 identified the areas of development, and later iterations of the plan can build on them as the systems evolve. Visions are broken down into key capabilities to be developed, which are then transformed into key programmes to achieve them (See Figure 13).

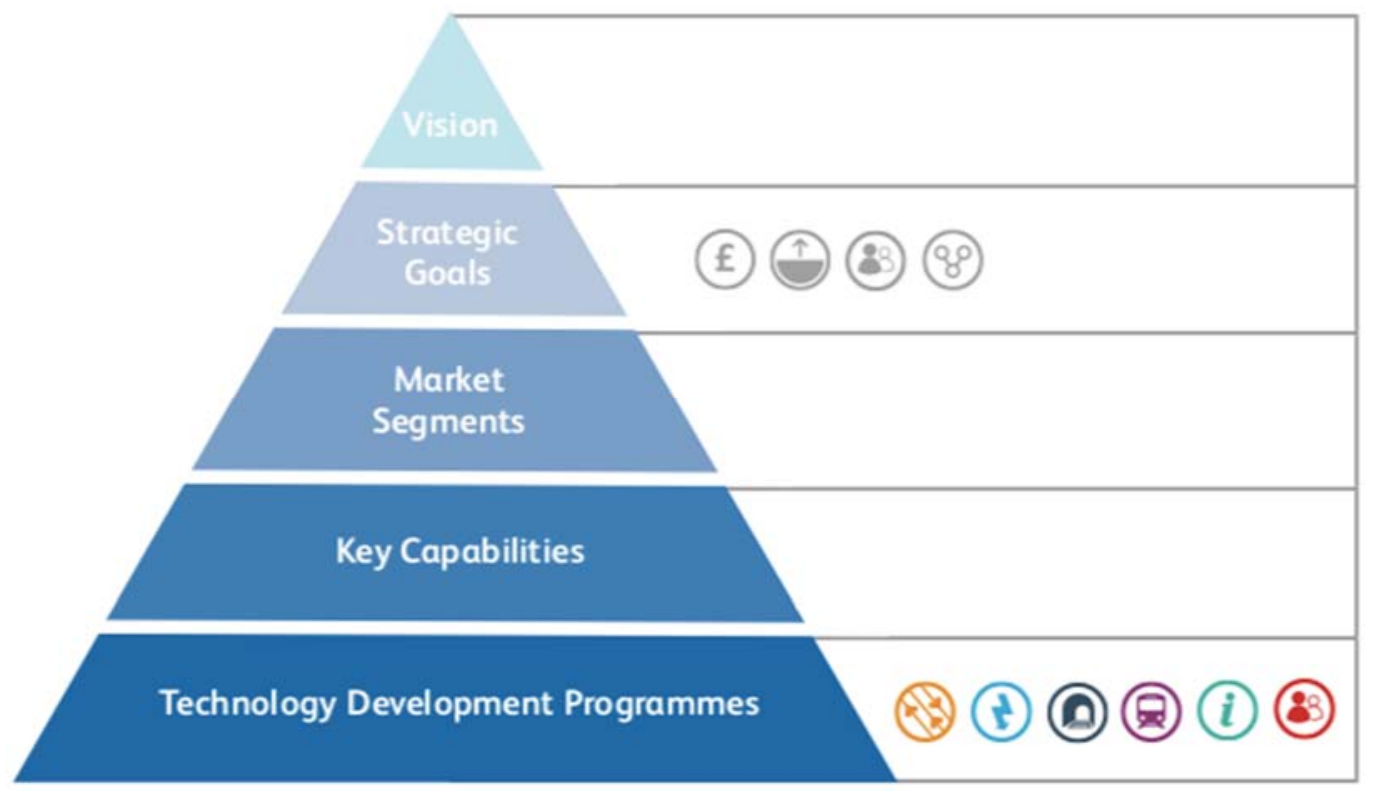

Figure 13. The U.K. Capability Delivery Plan [42]. 


\section{Developing a Technical Strategy for Low-Income Countries}

\subsection{Overview}

As previously mentioned, there are visions of a continent-wide railway network, specifically high-speed rail, in Sub-Saharan Africa and South Asia to facilitate trade as well as to sustainably meet the travel needs of the growing populations. A more specific vision for the African railway sector in 2040 was published in 2013 [5]. Its main focus is on the regeneration of railway networks, highlighting the need to consider transport networks at regional and continental levels.

This paper suggests a framework for a technical strategy to be used in the development of rail infrastructure in LICs in Sub-Saharan Africa and South Asia (Figure 14). Assuming a future goal of interoperable and efficient rail networks, eight main capabilities were identified considering the current state of rail infrastructure found in the literature. These are infrastructure, signaling, interoperability, planning, standards, costs, data, and safety.

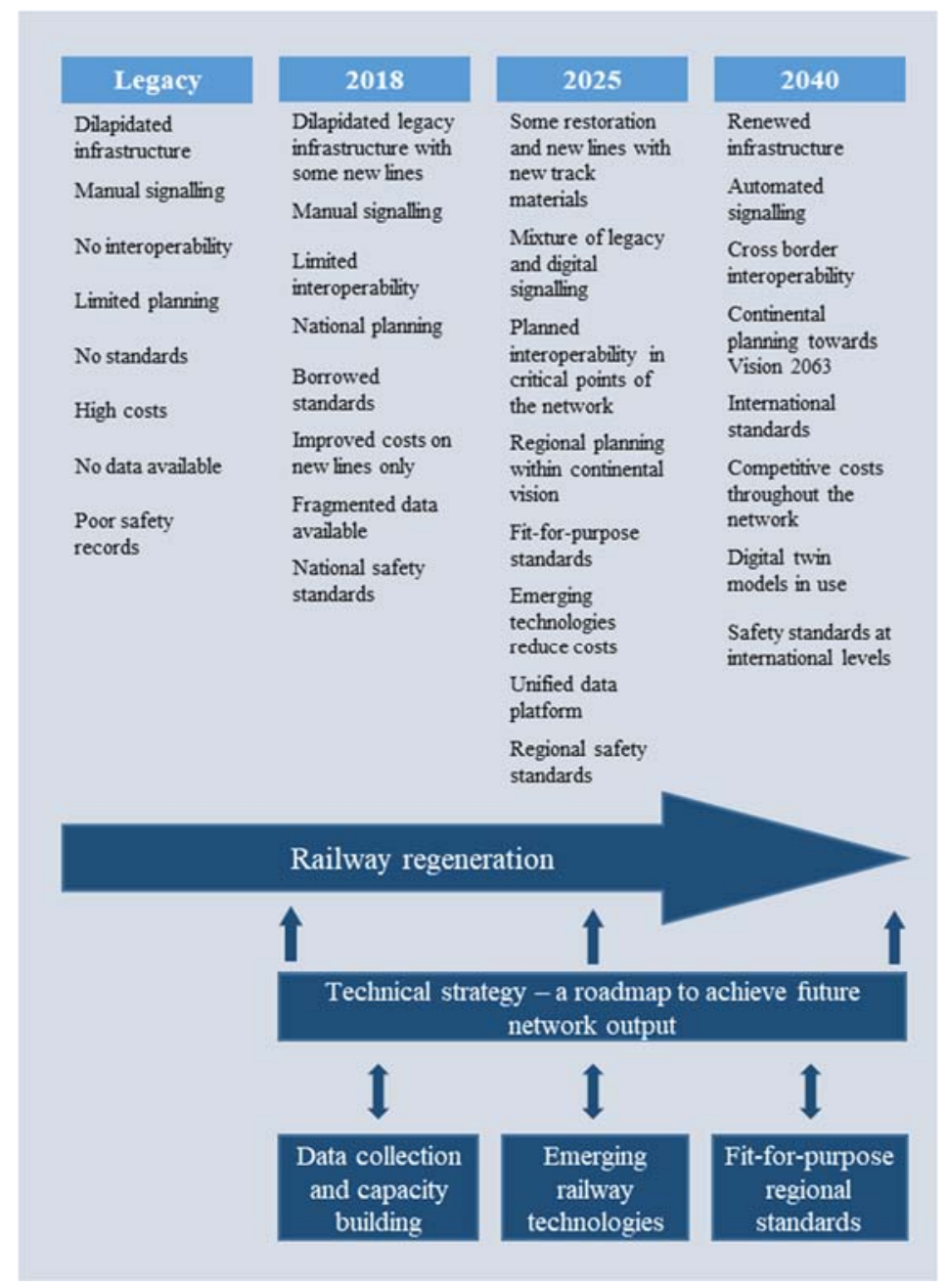

Figure 14. A technical strategy for developing rail infrastructure in low-income countries.

Currently, rail infrastructure in these LICs is mostly what is left from the legacy of the original networks of the 19th and 20th century, with little planning and almost no interoperability between countries. Most countries struggle with severely dilapidated infrastructure from years of negligence and poor maintenance. Traffic volumes are affected and so are the costs. Various track gauges have been found in bordering countries, challenging cross-border operations and limiting the competitiveness of 
railway transport with road-based modes. Some countries even operate different gauges within their own borders, creating operational difficulties that consume precious time and result in greater costs.

More important in the diagram are the intermediate milestones, which provide a systematic bridge between the current state and future goals of railway networks. It is crucial to acknowledge the incremental level of sophistication of the systems where appropriate cost-effective technologies can be implemented. Large scale projects such as railways take several years to be completed, meaning that the evolution of capabilities must be taken as a long-term process. Otherwise, localised initiatives such as those seen in Sino-African projects may become the norm, adopting unsustainable projects and unaffordable solutions for quick wins.

Based on regional documents outlining the vision for interoperable railway networks, we have established a maturity pathway for each of the capabilities. Similarly to processes conducted in Europe, they focus on outcomes and are kept "solution agnostic" in order to maintain the pool of potential technologies available. The framework also acknowledges previous and current projects of modernisation that have adopted international standards, but not in a cohesive manner.

There is a considerable gap between the desired state of rail infrastructure in 2040 and the current situation where countries are beginning to move away from legacy systems. However, there is also an advantage in the greater technological prowess available nowadays, which can help leapfrog the development path taken by high income countries. As an example, digitalisation and recent advances in traction and materials can reduce the costs of renovation, as well as achieve levels of interoperability and standardisation that have taken other countries much longer in the past.

The key outcomes of the strategy are found at the bottom of Figure 14 in the form of applied research programmes. Similarly to the European case, the role of a technical strategy for LICs is to bridge the desired capability development with applied and appropriate research programmes. The three main drivers identified in this research are: (i) data collection and capacity building; (ii) emerging railway technologies; and (iii) fit-for-purpose regional standards.

\subsection{Data Collection and Capacity Building}

Data was found to be a crucial capability, not only for the development of more efficient networks but also for the technical strategy itself. Many indicators of the current state of infrastructure and operational performance in low-income countries are not available. When they are, they are at least 10 years old, which renders them unreliable, especially in the context of accelerated economic growth seen in these countries. Little technical information has been found on the new projects from Sino-African and Sino-Asian agreements.

In this, data collection and capacity building become short-term priorities for the pathways of the technical strategy. However, the process must be systematic in identifying key performance indicators that can assess whether capability developments align with the future vision. Therefore, all countries in the region must agree on a list of indicators to be measured, the metrics to be used, and standard collection processes to ensure reliability in the results.

Building such capacity in data collection and benchmarking, LIC regions will become able to identify the different levels of each country and act accordingly. In addition, indicators can indicate gaps between current performance and each milestone, highlighting priority areas for research and development.

The advantage of using a technical strategy to guide data collection activities is that the type and amount of data is decided not on the current availability of the system but on the future vision of the networks. With this, when capabilities start to evolve, measures of effectiveness of past programs can be assessed, and new iterations of research and development (R\&D) initiatives decided accordingly. On the other hand, this paradigm requires a high level of transparency between all countries that take part in the technical strategy. This means that efforts need to be leveled and a baseline amount of information shared. 


\subsection{Emerging Railway Technologies}

Improved databases can then be used as a basis for the technical strategy to achieve the other two medium- and long-term outcomes. The technical strategy should use performance indicators to identify differentiated technologies that can provide technological shortcuts to achieve similar outcomes without having to follow the same path of high-income countries. It is important that the capabilities defined are solution agnostic because one of the key elements of technical strategies is the differentiation approach to rail infrastructure. This perspective suggests that a more cost-effective plan for the development of railway networks is based on differentiation at an infrastructure level as part of a wider multi-purpose strategy, where different types of operations can share some routes, while others will be largely used by a single sector.

Track renovation and renewal seem to be an early milestone to restore traffic efficiency in areas where the network has suffered most. Specific geometries, track density, and gauge must follow careful consideration of demand forecasts to differentiate international corridors from local lines. By doing so, improvements towards interoperability can start with more cost-effective routes and use appropriate technologies for each section. In the meantime, research programs can be started on solutions for moving assets and control and communication.

For instance, emerging digital signaling technologies can offer a more cost-effective transition between the current state of the infrastructure (2018) and the next milestone (2025), leapfrogging track-side equipment. One important advantage of digital technologies is the easier and more cost-effective upgrading when traffic increases in the network.

Similarly, a deeper and broader knowledge of track conditions and geometry can give way to bespoke wagon design and materials to achieve a certain performance at appropriate costs. The role of emerging railway technologies can prove crucial to accelerate and integrate the regional development of rail infrastructure in LICs in Sub-Saharan Africa and South Asia. Nonetheless, the situation encountered in those countries is one of fragmented capabilities and distinct standards. It logically follows that off-the-shelf solutions may not suffice, and that research initiatives should also look at solutions at the technology level.

\subsection{Fit-for-Purpose Regional Standards}

In the medium to long term, the adoption of emerging technologies in differentiated solutions can lead to agreements on regional standards. Fit-for-purpose standards can be elicited to cater for the specific operational paradigms encountered in low-development countries so that differentiated technologies can be used in a safe and reliable manner. Differentiated technologies comprise disruptive solutions that have the potential to save money (both in terms of initial cost and whole life cycle costs), while also providing greater capability, improved environmental impacts, and a better solution for customers. Adopting fit-for-purpose regional standards has the potential to create leading expertise regionally, and companies that are able to export products and expertise internationally.

In addition, having a coordinated approach to technology development creates markets for new fit-for-purpose technological solutions that consider the differentiated operating parameters in each region. Within this scenario, technical strategies such as the ones practiced in Europe help small and medium enterprises (SMEs) to access those specific regional markets.

There are challenges to be overcome. Regional standards that can foster local economies depend on collective and cohesive action between countries, and facilitated movement of products and people between borders. In addition, technical strategies usually channel funding streams centrally, requiring coordinated decisions from a central commission. These mechanisms are essential interfaces between the building blocks of the technical strategy that ensure its efficacy. 


\section{Conclusions and Discussion}

Railways are staging a comeback around the world as governments are changing policies and strategies to address sustainable development goals. Railway transport has the potential to be more sustainable and more affordable than road transport when economies of scale are made possible. They can reduce emissions and energy consumption per traffic unit, both in passenger-km and tonne- $\mathrm{km}$. However, low-income countries have been struggling to achieve this because of the current condition of their rail infrastructure. In most cases, tracks have been poorly maintained for decades, and little investment has been made to improve signaling systems and rolling stock technologies. As a result, most low-income countries analysed in this research produce low traffic densities as a measure of traffic units per kilometer of rail lines. With that, the operational costs per traffic unit becomes higher than in other parts of the world and reduces the competitiveness of rail against road transport.

This paper conducted a review on the current condition of infrastructure and operational performance of railways in low-income countries in Sub-Saharan Africa and South Asia. A total of 23 countries in Sub-Saharan Africa and 4 countries in South Asia were included in the study. Reliable datasets were found to be mostly outdated, and recent available data is fragmented. The review of the current state of the infrastructure confirms the general perception of the regions-assets dating back to colonial periods with little improvement since, and single-track routes with manual signaling systems limit the capacity of lines.

Despite the financial constraints, low-income countries in Sub-Saharan Africa and South Asia are following through and agreeing to various resource-for-infrastructure loans to build new lines to replace severely dilapidated existing networks. These plans seem to go in an opposite direction to a shared vision of continent-wide efficient rail networks that can provide a competitive alternative to road transport. Firstly, most of the lines planned have been driven by international suppliers' preferences and the financing available rather than as part of a coherent and coordinated development plan. As a result, some of the new lines suffer from the same interoperability issues as the original infrastructure from the beginning of the last century. Secondly, there have been concerns over the financial sustainability of these projects. They have been deployed with little consideration of specific requirements of the lines, resulting in technologies used in high-capacity networks being applied to the low traffic volumes currently found in the regions.

Further research is necessary to put such a technical strategy into practice:

1. As a starting point, data is a crucial aspect for a successful development of a technical strategy. There is very little data concerning the current state of railway infrastructure and the operational performance achieved. It is important that the current condition of assets and current performance levels are known so that specific technology roadmaps can be traced.

2. Specific research on emerging technologies that can provide cost-effective and more sustainable solutions for the specific operational context of low-income countries. Off-the-shelf technologies in use in countries with high volumes of traffic can be too costly and unsustainable in the long run. These include new traction solutions (e.g., hydrogen) that can bypass the need for expensive electrified networks, cost-effective materials for tracks and rolling stock, digitalised train-based signaling systems, etc.

3. A final part of the technical strategy relates to standards. In order to achieve efficient, interoperable, continent-wide rail networks, low-income regions need to ensure that the technologies adopted are standardised. If not, that they are at least compatible with cross-border operations. With the research on the use of emerging technologies for context-specific solutions, research should also develop fit-for-purpose regional standards in accordance with future visions. In addition, the creation of standards that are lacking in many LICs can promote improved operational performance, especially concerning safety. 
Therefore, this paper suggests that low-income countries in Sub-Saharan Africa and South Asia need to develop a technical strategy to coordinate localised development towards a common goal in order to achieve their visions. Technical strategies used in high-income countries are used as a baseline to define key processes in developing a counterpart for low-development countries so that they can find technological shortcuts rather than just follow the previous development paths of high-income regions. A framework for a technical strategy for LICs in Sub-Saharan Africa and South Asia was presented, in which eight capabilities were identified for priority. In addition, the framework proposes a structured mechanism to transform the three main areas of further research into practice and achieve the milestones elicited.

Future work should initially scan the current condition and performance of rail infrastructure in LICs in Sub-Saharan Africa and South Asia to update and equalise databases. Subsequently, once the local and regional gaps are identified, research programs can be devised in order to address the building blocks suggested. Using emerging technologies and adopting fit-for-purpose standards will facilitate these regions to achieve their capability milestones and achieve their future visions more efficiently.

Author Contributions: Data collection, M.B., W.W., and L.A.; workshop organisation, M.B. and C.R.; authorship, M.B., W.W., L.A., and C.R.

Funding: This project is part of the High Volume Transport (HVT) applied research programme funded by the UK Department for International Development (DFID)

Acknowledgments: This research was funded by UK AID through the UK Department for International Development under the High Volume Transport (HVT) Applied Research Programme, managed by IMC Worldwide. The authors are particularly grateful for the advice of Bruce Thompson the leader of Theme 1, Long Distance Strategic Road and Rail Transport, of the HVT Programme.

Conflicts of Interest: The authors declare no conflict of interest. 


\section{Appendix A}

\begin{tabular}{|c|c|c|c|c|c|c|c|c|c|}
\hline & $\begin{array}{c}\text { Total Track } \\
\text { (km) }\end{array}$ & $\begin{array}{c}\text { Track Density } \\
(\mathbf{k m} / \mathbf{1 0 0 0} \\
\left.\mathbf{k m}^{2}\right)\end{array}$ & $\begin{array}{l}\text { Km of Track } \\
\text { per Million } \\
\text { Inhabitants }\end{array}$ & $\begin{array}{c}\text { Number of } \\
\text { Carriages }\end{array}$ & $\begin{array}{c}\text { Number of } \\
\text { Wagons }\end{array}$ & $\begin{array}{c}\text { Labour } \\
\text { Productivity } \\
\text { (1000 Traffic Units } \\
\text { per Employee) }\end{array}$ & $\begin{array}{l}\text { Freight Traffic } \\
\text { Volume } \\
\text { (Million Net } \\
\text { Tonne-km) }\end{array}$ & $\begin{array}{c}\text { Passenger Traffic } \\
\text { Volume (Million } \\
\text { Passenger-km) }\end{array}$ & $\begin{array}{c}\text { Traffic Density } \\
\text { (1000 Transport } \\
\text { Units per } \\
\text { Route-km) }\end{array}$ \\
\hline Benin & 579 & 5.0 & 54 & 20 & 326 & 40.4 & 117 & 52 & 291.9 \\
\hline Burkina Faso & 622 & 2.3 & 34 & 29 & 657 & 481.0 & 360 & 58 & 672.0 \\
\hline Cote d'Ivoire & 639 & 2.0 & 28 & - & - & - & 376 & 60 & 682.3 \\
\hline DR Congo & 3641 & 1.6 & 47 & 233 & 3199 & 27.8 & 681 & 16 & 191.4 \\
\hline Eritrea & 117 & 1.2 & 17 & - & - & - & 0 & 0 & 0.0 \\
\hline Ethiopia & 681 & 0.7 & 7 & 27 & 493 & 70.9 & 189 & 111 & 440.5 \\
\hline Ghana & 947 & 4.2 & 35 & 154 & 489 & 84.1 & 298 & 69 & 387.5 \\
\hline Guinea & 1045 & 4.3 & 96 & - & - & - & 5760 & 38 & 5548.3 \\
\hline Kenya & 2065 & 3.6 & 45 & 328 & 7140 & 203.5 & 1858 & 333 & 1061.0 \\
\hline Liberia & 428 & 4.4 & 123 & - & - & - & 0 & 0 & 0.0 \\
\hline Madagascar & 886 & 1.5 & 39 & - & 187 & - & 37 & 0 & 41.8 \\
\hline Malawi & 797 & 8.5 & 47 & 17 & 478 & 131.0 & 91 & 27 & 148.1 \\
\hline Mali & 641 & 0.5 & 44 & 44 & 509 & 339.0 & 240 & 54 & 458.7 \\
\hline Mozambique & 3128 & 4.0 & 112 & 28 & 834 & 143.8 & 913 & 127 & 332.5 \\
\hline Nigeria & 3557 & 3.9 & 21 & 236 & 1299 & 37.2 & 160 & 108 & 75.3 \\
\hline Senegal & 1053 & 5.5 & 73 & 108 & 755 & 479.2 & 754 & 59 & 772.1 \\
\hline Sierra Leone & 84 & 1.2 & 13 & - & - & - & 0 & 0.0 & 0.0 \\
\hline Sudan & 4680 & 2.5 & 116 & 167 & 3949 & 76.7 & 946 & 58 & 214.5 \\
\hline Tanzania & 3691 & 4.2 & 72 & 216 & 3600 & 305.5 & 2389 & 586 & 806.0 \\
\hline Togo & 522 & 9.6 & 84 & - & - & - & 195 & 20 & 411.9 \\
\hline Uganda & 1244 & 6.3 & 36 & 21 & 1289 & 155.9 & 211 & 0 & 169.6 \\
\hline Zambia & 2164 & 2.9 & 140 & 21 & 1150 & 502.0 & 1176 & 248 & 658.0 \\
\hline Zimbabwe & 3227 & 8.3 & 247 & 314 & 10713 & 389.9 & 3170 & 457 & 1124.0 \\
\hline Afghanistan & 277 & 0.4 & 8 & - & - & - & - & - & - \\
\hline Bangladesh & 2874 & 22.1 & 17 & 1476 & - & 343.6 & 677 & 8135 & 3066.1 \\
\hline Myanmar & 6207 & 9.5 & 116 & 1375 & 3384 & 241.5 & 887 & 5307 & 997.9 \\
\hline Pakistan & 7791 & 8.8 & 40 & 1636 & 16085 & 389.6 & 6073 & 22476 & 3664.4 \\
\hline
\end{tabular}




\section{References}

1. World Bank. Data Bank: Railways. Available online: https://data.worldbank.org (accessed on 18 April 2019).

2. Borin, E.; Guivarch, C. Transport infrastructure costs in low-carbon pathways. Transp. Res. Part D 2017, 55, 389-403. [CrossRef]

3. Bullock, R. Off-Track: SSA Railways; The World Bank: Washington, DC, USA, 2009.

4. AfDB. Rail Infrastructure in Africa: Financing Policy Options; African Development Bank: Abidjan, Cote d'Ivoire, 2015.

5. UIC. Railway Revitalization in Africa-Destination; International Union of Railways: Paris, France, 2013.

6. Olievschi, V.N. Railway Transport: Framework for Improving Railway Sector Performance in SSA; The World Bank: Washington, DC, USA, 2013.

7. African Union Commission. Agenda 2063: The Africa We Want; African Union Commission: Addis Ababa, Ethiopia, 2014.

8. The World Bank. World Bank Country and Lending Groups. Available online: https://datahelpdesk. worldbank.org/knowledgebase/articles/906519-world-bank-country-and-lending-groups (accessed on 2 April 2019).

9. DFID. Where We Work. Available online: https://www.gov.uk/guidance/where-we-work (accessed on 2 April 2019).

10. The World Bank. African Infrastructure: Railways. Available online: https://databank.worldbank.org/data/ source/africa-infrastructure:-railways (accessed on 23 March 2019).

11. UIC. RAILISA Statistics. Available online: https://uic-stats.uic.org (accessed on 29 April 2019).

12. Bangladesh Railway. Rail Master Plan; Government of Bangladesh: Dhaka, Bangladesh, 2013.

13. Asian Development Bank. Myanmar Transport Sector Policy Note: Railways; Asian Development Bank: Mandaluyong, Philippines, 2016.

14. Ministry of Rail Transportation. Developing a Myanmar's Rail Network that Meet Demands; Government of Myanmar: Naympyitaw, Myanmar, 2015.

15. Pakistan Railways. Yearbook 2016; Ministry of Railways of the Government of Pakistan: Lahore, Pakistan, 2017.

16. Habiyareme, A. Is Sino-African trade exacerbating resource dependence in Africa? Struct. Chang. Econ. Dyn. 2016, 37, 1-12. [CrossRef]

17. Eurostat. Railway Transport Database. Available online: https://ec.europa.eu/eurostat/data/database (accessed on 15 April 2019).

18. Morlin-Yron, S. All Aboard! The Chinese-Funded Railways Linking East Africa. Available online: https: //edition.cnn.com/2016/11/21/africa/chinese-funded-railways-in-africa/index.html (accessed on 15 April 2019).

19. Gopalakrishnan, S. In Search of a Smoother Ride on Narrow Gauge Track. Available online: https://www.railwaygazette.com/news/single-view/view/in-search-of-a-smoother-ride-on-narrowgauge-track.html (accessed on 15 April 2019).

20. European Union. Commission Decision 2004/446/EC of 29 April; European Union: Brussels, Belgium, 2004.

21. Delelegn, M. The hottest projects in Ethiopia and what is being done to open for investments. In Proceedings of the East Africa Rail Conference, Nairobi, Kenya, 21-22 November 2018.

22. UIC. Railway Statistics: 2015 Synopsis; International Union of Railways: Paris, France, 2015.

23. JICA. Pakistan Transport Plan Study in the Islamic Republic of Pakistan; Japan International Cooperation Agency: Tokyo, Japan, 2008.

24. Ahmed, B.N.; van der Windt, N.; van Rijsbergen, B. Railway Signalling and Interlocking in Bangladesh; Erasmus University of Rotterdam: Rotterdam, The Netherlands, 2015.

25. Railway Gazette. Myanmar Signalling Contract Signed. Available online: https://www.railwaygazette.com/ news/news/asia/single-view/view/myanmar-signalling-contract-signed.html (accessed on 10 December 2018).

26. Asian Development Bank. \$1.5 Billion ADB Rail Project will Develop Southeast Bangladesh. Available online: https://www.adb.org/news/15-billion-adb-rail-project-will-develop-southeast-bangladesh (accessed on 29 April 2019).

27. Railway Gazette. Work to Begin on Chad Rail Network. Available online: https://www.railwaygazette.com/ news/infrastructure/single-view/view/work-to-begin-on-chad-rail-network.html (accessed on 29 April 2019). 
28. Samseer, M. Mali Signs $\$ 11 \mathrm{bn}$ Agreements with China for New Rail Projects. Available online: https://www.railway-technology.com/uncategorised/newsmali-signs-agreements-with-china-fornew-rail-projects-4375202/ (accessed on 29 April 2019).

29. Odditah, C. FG, CCECC Sign $\$ 11.117$ Billion Lagos-Calabar Rail Contract. Available online: https://guardian. ng/news/fg-ccecc-sign-11-117-billion-lagos-calabar-rail-contract (accessed on 29 April 2019).

30. Railway Technology. Abuja-Kaduna Rail Line. Available online: https://www.railway-technology.com/ projects/abuja-kaduna-rail-line (accessed on 29 April 2019).

31. Railway Gazette. Padma Bridge Rail Link Contract Awarded. Available online: https://www.railwaygazette. com/news/infrastructure/single-view/view/padma-bridge-rail-link-contract-awarded.html (accessed on 10 March 2019).

32. Bukhari, M. Pakistan Cuts Chinese 'Silk Road' Rail Project by $\$ 2$ Billion due to Debt Concerns. Available online: https://www.reuters.com/article/us-pakistan-silkroad-railways/pakistan-cuts-chinese-silk-road-railproject-by-2-billion-due-to-debt-concerns-idUSKCN1MB2V8 (accessed on 29 April 2019).

33. Ndukwe, L. Getting Nigeria's Railways Back on Track with China's Help. Available online: https: //www.bbc.co.uk/news/world-africa-42172955 (accessed on 29 April 2019).

34. Mourdoukoutas, P. China is Doing the Same Things to Sri Lanka that Great Britain did to China after the Opium Wars. Available online: https://www.forbes.com/sites/panosmourdoukoutas/2018/06/28/china-is-doing-thesame-things-to-sri-lanka-great-britain-did-to-china-after-the-opium-wars/\#298adeba7446 (accessed on 7 April 2019).

35. Kacungira, N. Will Kenya Get Value for Money from Its New Railway? Available online: https://www.bbc.co. uk/news/world-africa-40171095 (accessed on 7 April 2019).

36. Rahmatullah, M. Transport issues and integration in South Asia. In Promoting Economic Cooperation in South Asia: Beyond SAFTA; Ahmed, S., Kelegama, S., Ghani, E., Eds.; The World Bank: Washington, DC, USA, 2010; pp. 174-194.

37. Railway Gazette. ERTMS Regional Contract in Zambia. Available online: https://www.railwaygazette.com/ news/infrastructure/single-view/view/ertms-regional-contract-in-zambia.html (accessed on 29 April 2019).

38. European Commission. Mobility and Transport. Available online: https://ec.europa.eu/transport/modes/ rail_en (accessed on 3 April 2019).

39. EIM. European Railway Technical Strategy: Technical Vision to Guide the Development of TSIs; European Rail Infrastructure Managers: Brussels, Belgium, 2008.

40. UIC. Railway Technical Strategy Europe; International Union of Railways: Paris, France, 2019.

41. European Commission. Rail Research and Shift2Rail. Available online: https://ec.europa.eu/transport/modes/ rail/shift2rail_en (accessed on 25 July 2019).

42. RSSB. Rail Technical Strategy: Capability Delivery Plan; Rail Safety and Standards Board: London, UK, 2017. 